\title{
In vivo and in vitro anti-inflammatory activity of Cryptostegia grandiflora Roxb. ex R. Br. leaves
}

\author{
Jenny P Castro, Yanet C Ocampo and Luis A Franco*
}

\begin{abstract}
Background: Despite Cryptostegia grandiflora Roxb. ex R. Br. (Apocynaceae) leaves are widely used in folk Caribbean Colombian medicine for their anti-inflammatory effects, there are no studies that support this traditional use. Therefore, this work aimed to evaluate the effect of the total extract and primary fractions obtained from Cryptostegia grandiflora leaves, using in vivo and in vitro models of inflammation, and further get new insights on the mechanisms involved in this activity.

Results: Ethanolic extract of Cryptostegia grandiflora leaves, and its corresponding ether and dichloromethane fractions, significantly reduced inflammation and myeloperoxidase activity (MPO) in ear tissue of mice treated with 12-O-tetradecanoyl-phorbol-13-acetate (TPA). Histological analysis revealed a reduction of edema and leukocyte infiltration. Complementarily, we demonstrated that extract and fractions reduced nitric oxide (NO.) and prostaglandin E2 (PGE2) production in LPS-stimulated RAW 264.7 macrophages, as well as scavenging activity on DPPH and ABTS radicals.

Conclusions: Our results demonstrated for the first time the anti-inflammatory activity of Cryptostegia grandiflora leaves, supporting its traditional use. This activity was related to inhibition of MPO activity, and PGE2 and NO• production. These mechanisms and its antioxidant activity could contribute, at least in part, to the anti-inflammatory effect showed by this plant.
\end{abstract}

Keywords: Ear edema, Free radicals, Inflammation, MPO, PGE2, RAW 264.7 macrophages

\section{Background}

Harmful stimuli to body, such as pathogens, damaged cells or physical injury, are able to trigger an inflammatory response. When this response is persistent, chronic inflammation appears as an undesirable phenomenon that can lead to the development of severe diseases such as osteoarthritis, rheumatoid arthritis, gout, asthma, inflammatory bowel disease, diabetes, cancer, cardiovascular disease and neurodegenerative disorders, which represent an important cause of morbidity and mortality worldwide [1-3].

Macrophages are considered the main immune effector cells, playing a pivotal role in tissue damage in a great number of inflammatory conditions, both acute and chronic. Activated macrophages are able to synthesize reactive oxygen species (radical superoxide $\cdot \mathrm{O}_{2}^{-}$,

\footnotetext{
* Correspondence: Ifrancoo@unicartagena.edu.co

Biological Evaluation of Promissory Substances Group, Faculty of

Pharmaceutical Sciences, University of Cartagena, Cartagena 130015 Colombia
}

(c) 2014 Castro et al.; licensee BioMed Central Ltd. This is an Open Access article distributed under the terms of the Creative Commons Attribution License (http://creativecommons.org/licenses/by/4.0), which permits unrestricted use, distribution, and reproduction in any medium, provided the original work is properly credited. The Creative Commons Public Domain Dedication waiver (http://creativecommons.org/publicdomain/zero/1.0/) applies to the data made available in this article, unless otherwise stated. hydrogen peroxide $\mathrm{H}_{2} \mathrm{O}_{2}$, and the highly reactive hydroxyl radical $\bullet \mathrm{OH}), \mathrm{NO} \cdot$, arachidonic acid metabolites, and lysosomal enzymes which are necessary to perform their phagocytic function. These cells also play an important role in the development of various chronic diseases such as cancer and allergies [4-6].

Traditional medicine has been a revealing source of new molecules in modern drug discovery, thus the use of herbal medicines or their active components represents an increasingly explored and promissory alternative for the treatment of numerous diseases, including inflammatory disorders [7]. The application of natural products in traditional medical systems of many countries is due to a current trend towards the use of green products because they are considered safer. However, limited scientific evidence regarding to the effectiveness of natural bioactive derivatives, in addition to a limited understanding of the mechanisms of action related with their biological activity, has limited its incorporation into clinical practice [8-10]. 
Considering the folk use of Cryptostegia grandiflora Roxb. ex R. Br. (Apocynaceae) on inflammatory conditions, which was revealed by ethnobotanical studies conducted by research groups at the University of Cartagena in the Colombian Caribbean region, and that no information is available about its topical anti-inflammatory properties, we investigated the effect of the total ethanolic extract and primary fractions obtained from the leaves of this plant using a murine model of topical inflammation. Additionally to further get new insights into the possible mechanisms involved in this activity, we evaluated the effect on PGE2 and NO- production, MPO activity and scavenging of the free radicals DPPH, ABTS, and NO.

\section{Results and discussion}

\section{Anti-inflammatory activity}

Cryptostegia grandiflora also known in Colombian Caribbean coast as "20 de Julio or Flor de Muerto" and rubber vine in English speaking countries, is a perennial woody shrub widely distributed in Madagascar, India, South Florida and tropical regions [11-13]. Due to its high latex content, Cryptostegia grandiflora is employed in the manufacture of rubber and as a source of hydrocarbon fuels [11]. However, the interest in this plant is not restricted to its industrial applications, but rather to its usages in folk medicine as hypoglycemic, coagulant, antibacterial, anti-inflammatory, anti-asthmatic and for the treatment of nervous disorders [13-17], representing a promissory source of bioactive secondary metabolites. Consequently, several research groups have corroborated many of the biological activities mentioned above. However, to our knowledge, this is the first report of the anti-inflammatory activity of Cryptostegia grandiflora leaves.

TPA-induced ear edema model is a valid model to effectively screen compounds with anti-inflammatory potential. Topical application of TPA induces an inflammatory response associated with edema formation and increased MPO activity [18-20]. This is consistent with the results obtained in our study, where topical application of TPA induced a severe inflammatory response in mouse ear that resulted in massive edema formation which was evident by the increased ear weight in comparison with control group, only treated with acetone $(\mathrm{p}<0.001)$. Total extract and ether and dichloromethane fractions from Cryptostegia grandiflora significantly reduced inflammation induced by TPA, with inhibition percentages higher than $40 \%$, similar to that produced by indomethacin, which was used as positive control, whereas methanol fraction did not exert anti-inflammatory effects (Table 1). None of the tested extract/fractions produced evident adverse local or systemic effects, suggesting that their topical administration is well tolerated. Due to the lack of bioactivity
Table 1 Topical anti-inflammatory effect of the total extract and primary fractions obtained from Cryptostegia grandiflora leaves

\begin{tabular}{llll}
\hline Treatment & $\begin{array}{l}\text { Dose } \\
\text { (mg/ear) }\end{array}$ & $\begin{array}{l}\text { Ear weight } \\
\text { differences }(\mathbf{m g})\end{array}$ & $\begin{array}{l}\text { Inhibition } \\
\text { percentage (\%) }\end{array}$ \\
\hline Control (TPA + acetone) & --- & $13.5 \pm 0.6$ & --- \\
Indomethacin & 0.5 & $7.4 \pm 0.8$ & $52.4 \pm 6.2^{* * *}$ \\
$\begin{array}{l}\text { Cryptostegia grandiflora } \\
\text { Total extract }\end{array}$ & 1.0 & $7.6 \pm 0.1$ & $42.1 \pm 0.9^{* * *}$ \\
$\begin{array}{l}\text { Ether fraction } \\
\begin{array}{l}\text { Dichloromethane } \\
\text { fraction }\end{array}\end{array}$ & 1.0 & $8.1 \pm 0.8$ & $41.8 \pm 8.0^{* * *}$ \\
Methanol fraction & 1.0 & $6.1 \pm 0.5$ & $52.9 \pm 4.3^{* * *}$ \\
\end{tabular}

Results are expressed as mean \pm S.M.E. $(n=6)\left({ }^{* * *} \mathrm{p}<0.001\right.$ ANOVA, statistically significant compared with control group).

of methanol fraction in the in vivo model, we selected the total extract and ether and dichloromethane fractions of Cryptostegia grandiflora to further evaluate their histopathological effect and the inhibition of MPO activity.

TPA promoted a marked increase in ear thickness, with clear evidence of edema, substantial neutrophil infiltration, and hyperplasia and hypertrophy of dermis and epidermis (Figure 1B). Treatment with Cryptostegia grandiflora total extract (Figure 1D) and ether (Figure 1E) and dichloromethane fractions (Figure 1F) notably reduced the total score, established by a blinded pathologist, over $45 \%$.

\section{MPO activity}

TPA treatment induced an increase in the tissue MPO activity. Ether and dichloromethane fractions from Cryptostegia grandiflora have a significant inhibitory effect on the activity of this enzyme by over $96 \%$, showing higher activity than the positive control indomethacin (Table 2), which showed inhibition of $77.7 \pm 2.2 \%$.

Treatment with total extract of Cryptostegia grandiflora leaves reduced inflammation and MPO activity in ear tissue. Such bioactivity is kept in its ether and dichloromethane fractions, which have different polarity, suggesting the presence of structurally diverse phytoconstituents that might be exerting its activity by different molecular mechanisms, contributing additively to the global anti-inflammatory effect. These results are very promissory since tested fractions constitute a mixture of many secondary metabolites, providing the first step of a bio-guided isolation conducted to isolate compounds with higher anti-inflammatory activity. Complementarily, our results suggests the usefulness of Cryptostegia grandiflora extracts and primary fractions to treat inflammatory skin diseases, including psoriasis and atopic dermatitis, without exerting signals of 

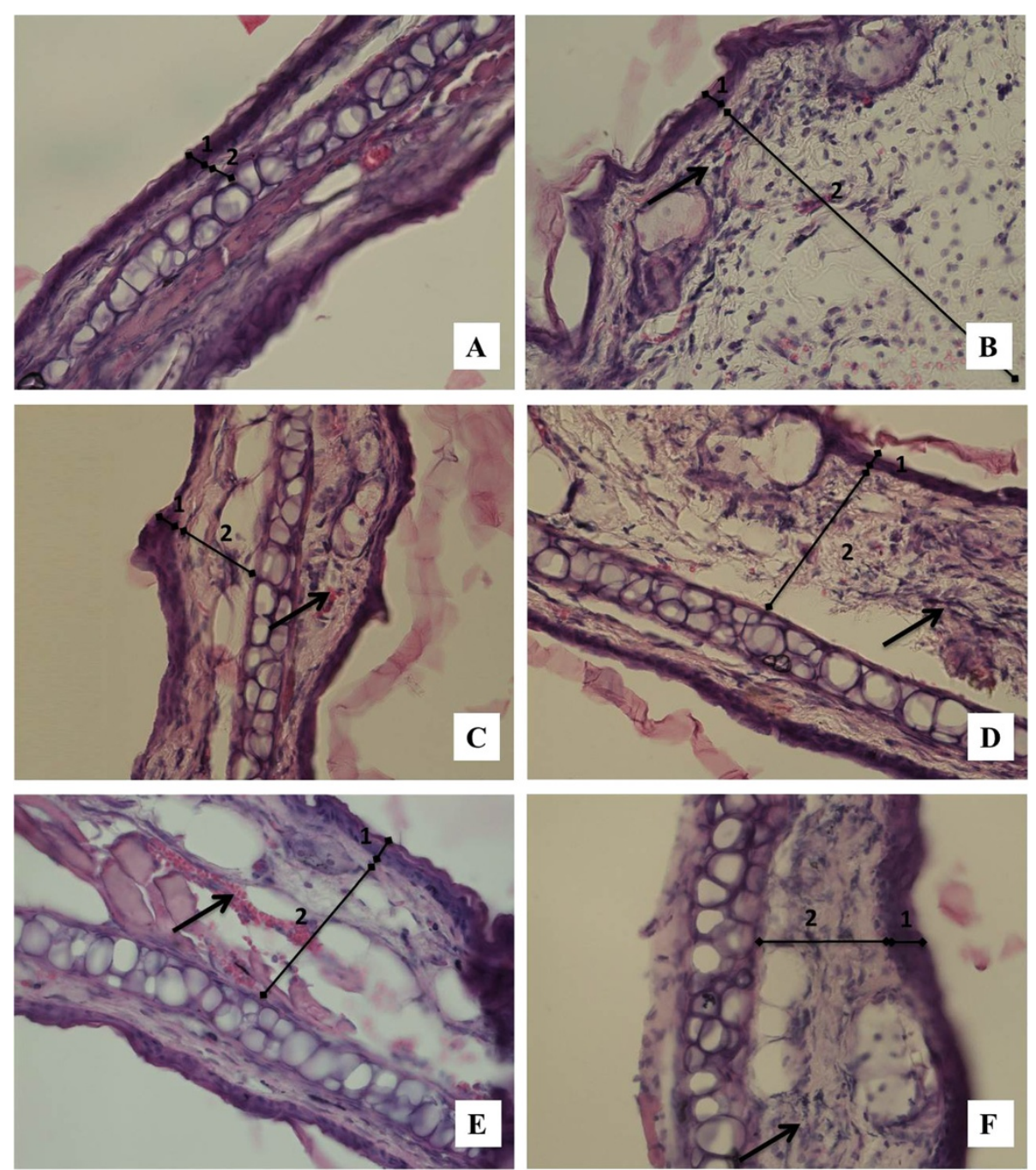

Figure 1 Histopathological changes produced by total extract and primary fractions of Cryptostegia grandiflora, qualified by a blinded pathologist. Pictures represents sections from mice ears stained with hematoxylin and eosin (40X) from: (A) Healthy group, (B) Control group (TPA, $2.5 \mathrm{\mu g} /$ ear), (C) TPA and Indomethacin (0.5 mg/ear), (D) TPA and Cryptostegia grandiflora total extract (1.0 mg/ear), (E) TPA and Cryptostegia grandiflora ether fraction (1.0 mg/ear), and (F) TPA and Cryptostegia grandiflora dichloromethane fraction (1.0 mg/ear). The numbers 1 and 2 indicate epidermis and dermis, respectively. Arrows indicate cell infiltration into the dermis.

Table 2 Effect of total extract and primary fractions obtained from Cryptostegia grandiflora leaves on MPO activity in ear tissue

\begin{tabular}{llll}
\hline Treatment & $\begin{array}{l}\text { Dose } \\
\text { (mg/ear) }\end{array}$ & $\begin{array}{l}\text { MPO activity } \\
\text { (U/mg of tissue) }\end{array}$ & $\begin{array}{l}\text { Inhibition } \\
\text { percentage (\%) }\end{array}$ \\
\hline Control (TPA + acetone) & --- & $18150 \pm 2012.3$ & - \\
Indomethacin & 0.5 & $4040 \pm 406.9$ & $77.7 \pm 2.2^{* * *}$ \\
$\begin{array}{l}\text { Cryptostegia grandiflora } \\
\text { Total extract }\end{array}$ & 1.0 & $11040 \pm 987.8$ & $39.1 \pm 5.4^{* * *}$ \\
Ether fraction & 1.0 & $600 \pm 89.4$ & $96.6 \pm 0.4^{* * *}$ \\
Dichloromethane fraction & 1.0 & $666 \pm 98.8$ & $96.3 \pm 0.5^{* * *}$
\end{tabular}

Results are expressed as mean \pm S.M.E. $(n=6){ }^{* * *} p<0.001$ ANOVA, statistically significant compared with control group). systemic toxicity. However, a detailed study of toxicity and dermal absorption will warrant its safety use as phytotherapy.

Overall, the anti-inflammatory effect of ether and dichloromethane fractions of Cryptostegia grandiflora is similar or higher to that observed for indomethacin, anti-inflammatory drug used as a reference [21,22]. Therefore, these promissory fractions were selected to evaluate their effect on NO and PGE2 production by LPS-induced macrophages RAW 264.7 and their scavenging effect of DPPH, ABTS and NO radicals, in order to get further insights into the mechanisms related with the antiinflammatory activity. 


\section{In vitro effect of Cryptostegia grandiflora on RAW 264.7 macrophages viability}

Macrophages activation with LPS induces the production of NO and PGE2, two potent pro-inflammatory mediators [23]. NO acts as signaling molecule that promotes growth and activity of immune cells [24]. Meanwhile, PGE2 induces arteriolar vasodilatation, increasing of vascular permeability and corporal temperature, and the pain produced by bradykinin, and serotonin [25]. In this sense, reducing the production of these inflammatory mediators is considered an alternative to prevent or treat complications associated with diseases related with inflammatory processes.

To guarantee that test fractions do not cause cell death, we assessed their effect on cell viability employing MTT assay. As can be seen in Figure 2, cell viability for all tested concentrations of Cryptostegia grandiflora fractions was similar to that obtained for control group (not treated cells), with viability percentages over $95 \%$. In this way, concentrations below $75 \mu \mathrm{g} / \mathrm{mL}$ can be securely evaluated using macrophages RAW 264.7.

\section{Inhibitory activity of Cryptostegia grandiflora on NO- and PGE2 production induced by LPS}

Treatment with LPS to RAW 264.7 macrophages induced synthesis and release of NO• and PGE2. Upon exposure to LPS, macrophages increased nitrite production, of up to $21.9 \pm 0.7 \mu \mathrm{M}$, whereas cells in resting state released trace amounts of NO•. $1400 \mathrm{~W}$, a selective inhibitor of inducible nitric oxide synthase (iNOS), caused a decrease in LPS-induced NO production by more than $70 \%$ at $10 \mu \mathrm{M}$.

Ether and dichloromethane fractions from Cryptostegia grandiflora diminished the production of $\mathrm{NO} \cdot$ in a concentration-dependent manner, reducing significantly nitrite concentration in culture medium compared to the group treated with LPS alone (Figure 3A and $3 \mathrm{~B})$. On the other hand, ether and dichloromethane fractions did not show scavenging effects on NO. free radical (data not shown), therefore the reduction of nitrite concentration can be attributed directly to a blockade in NO production in LPS-induced RAW 264.7 macrophages.
Macrophages RAW 264.7, in resting state, released $44.2 \pm 11.3 \mathrm{pg} / \mathrm{mL}$ of PGE2 during $24 \mathrm{~h}$ of incubation. However, upon exposure to LPS alone, the macrophages increased PGE2 production, of up to $3532.3 \pm 32.1 \mathrm{pg} / \mathrm{mL}$ (80 fold increase). Levels of LPS-induced PGE2 were decreased by ether and dichloromethane fractions of Cryptostegia grandiflora $(75 \mu \mathrm{g} / \mathrm{mL})$ to $1583.5 \pm 15.9$ and $1980.6 \pm 143.4 \mathrm{pg} / \mathrm{mL}$, respectively. In general, ether fraction was more potent than dichloromethane, diminishing levels of PGE2 in a dose dependent-manner, corresponding to a $59.6 \%$ at $75 \mu \mathrm{g} / \mathrm{mL}, 49.2 \%$ at $50 \mu \mathrm{g} / \mathrm{mL}$, and $44.8 \%$ at $25 \mu \mathrm{g} / \mathrm{mL}$, whereas dichloromethane fraction was only active at the highest test concentration producing $56.1 \%$ of inhibition (Figure $3 \mathrm{C}$ and $3 \mathrm{D}$ ).

The above date demonstrated that ether and dichloromethane fractions from Cryptostegia grandiflora leaves decreased the production of NO- and PGE2. This inhibitory effect might be contributing significantly to the mechanism of the in vivo anti-inflammatory effect of tested fractions.

\section{Anti-oxidant activity}

Cryptostegia grandiflora fractions, showed a potent scavenging effect of DPPH and ABTS free radicals, in a concentration-dependent manner, with $\mathrm{IC}_{50}$ values lower than 550 and $101 \mu \mathrm{g} / \mathrm{mL}$, respectively (Table 3). Even though these fractions did not present comparable activity to that presented by ascorbic acid, used as reference control; they constitute a promissory source to isolate bioactive compounds with antioxidant properties, as these complex fractions are constituted by an elevated number of compounds.

Considering that inflammatory processes, especially those which are presented chronically, are associated with an overproduction of free radicals that induce oxidative stress and cause the onset of various degenerative diseases $[9,26]$, and the potent scavenging effect of $\mathrm{DPPH}$ and ABTS free radicals exerted by ether and dichloromethane fractions of Cryptostegia grandiflora, we consider that the important antioxidant activity of this plant might be a key contributing factor to the reduction of edema in animals treated with TPA. Analgesic activity of a methanolic extract of leaves of Cryptostegia
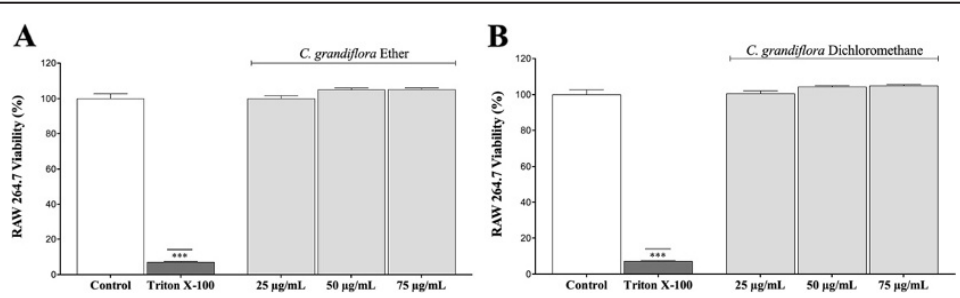

Figure 2 Effect of (A) ether and (B) dichloromethane fractions obtained from Cryptostegia grandiflora on cell viability of RAW 264.7 macrophages. Cytotoxicity was measured with MTT assay. Each value represents mean \pm S.E.M. $(n=15) .{ }^{* *} p<0.001$, compared with control group. 

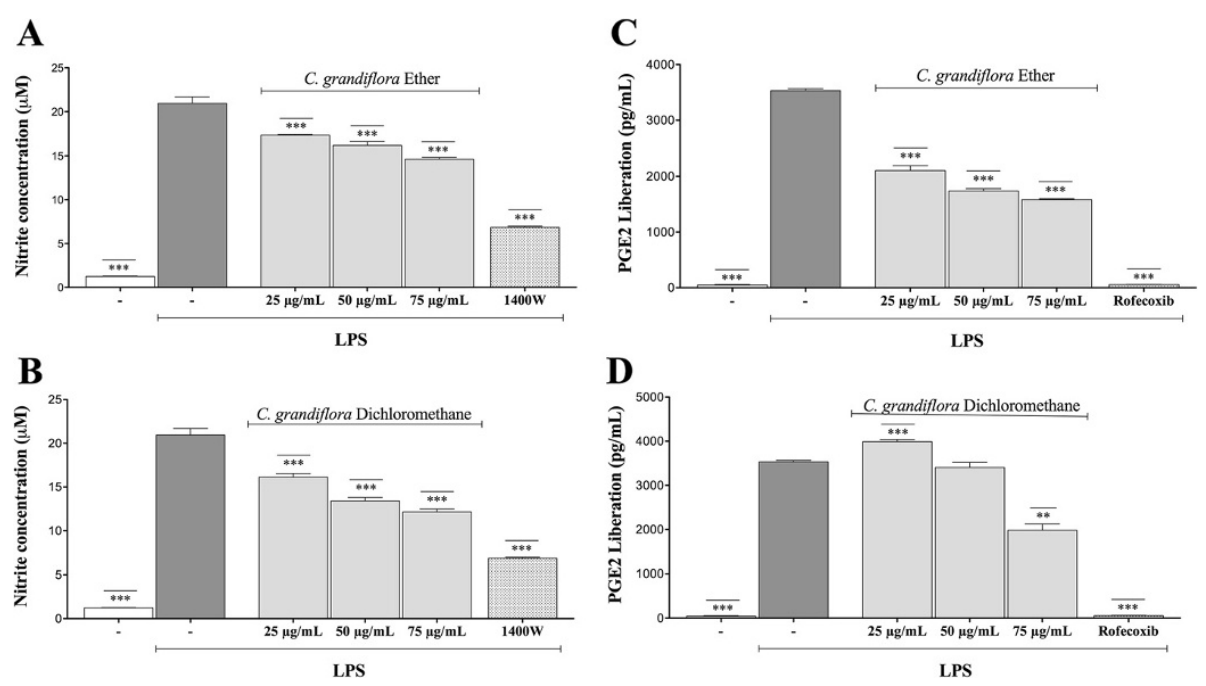

Figure 3 Inhibitory effect on NO• and PGE2 production by ether (A and C) and dichloromethane (B and D) fractions from Cryptostegia grandiflora on RAW 264.7 cells stimulated with LPS $(\mathbf{1 0} \boldsymbol{\mu g} / \mathbf{m L})$ for $\mathbf{2 4} \mathbf{~ h . ~} 1400 \mathrm{~W}(10 \mu \mathrm{M})$ and Rofecoxib $(10 \mu \mathrm{M})$ were employed as positive controls. Nitrite concentration in the culture medium was measured with the Griess reagent. PGE2 production was determined using a competitive ELISA kit (R\&D Systems, USA). Experiments were carried out in triplicate and results show the mean \pm S.E.M. $(n=12) .{ }^{* *} p<0.01,{ }^{* * *} p<0.001$, compared with LPS treated group.

grandiflora was recently described, attributing the significant pain reduction to the presence of flavonoids, alkaloids, tannins, saponins, terpenoids and phenolic compounds, especially to flavonoids and alkaloids analgesic principles acting against PG pathway and oxidative stress [27]. Considering that flavonoids has been described as anti-inflammatory compounds with several mechanism explaining their effect, including antioxidant and radical scavenging activities and modulation of the activities of arachidonic acid metabolism enzymes (phospholipase A2, cyclooxygenase and lipooxygenase) and nitric oxide synthase, their presence in leaves extracts of Cryptostegia grandiflora can be directly related to the anti-inflammatory activity demonstrated by us [28].

Table 3 Antioxidant activity of ether and dichloromethane fractions from Cryptostegia grandiflora leaves

\begin{tabular}{lll}
\hline DPPH & $\mathbf{I C}_{\mathbf{5 0}}(\boldsymbol{\mu \mathbf { g }} / \mathbf{m L})$ & $\begin{array}{l}\text { Confidence intervals } \\
(\boldsymbol{\mu g} / \mathbf{m L})\end{array}$ \\
\hline Ascorbic acid & 10.9 & $(10.2-11.8)$ \\
Ether fraction & 549.2 & $(505.3-593.5)$ \\
Dichloromethane fraction & 485.9 & $(440.9-531.0)$ \\
ABTS & & \\
Ascorbic acid & 2.3 & $(2.1-2.4)$ \\
Ether fraction & 101.0 & $(92.7-109.2)$ \\
Dichloromethane fraction & 96.9 & $(80.9-112.2)$ \\
\hline
\end{tabular}

Results are expressed as mean \pm S.M.E. $(n=9)$.
Conversely, the soluble protein fraction from the whole latex of Cryptostegia grandiflora has been described to induce a consistent inflammatory activity in different experimental models in vivo, regardless the administration route [12]. In this respect the latex of Cryptostegia grandiflora appears to be different from that of Calotropis procera Ait, R.Br (Apocynaceae), which produces both pro-inflammatory and anti-inflammatory effects depending on the protein content and administration route [29]. Our results, might suggest that latex contains different classes of proteins and secondary metabolites with contrasting bioactivities, providing a plentiful field for new research.

In conclusion, further work is needed in order to identify the specific antioxidant and anti-inflammatory compounds, as well as to clarify the potential synergic effects that might help to explain the mechanism of Cryptostegia grandiflora extract and fractions.

\section{Conclusions}

Our study demonstrated the anti-inflammatory activity of the extract and primary fractions obtained from the leaves of Cryptostegia grandiflora, which appears to be the first report establishing this biological activity and supporting the folk use of this plant in the Colombian Caribbean region. The promissory results obtained in this work constitutes the basis for further studies aiming to isolate, purify and characterize the bioactive anti-inflammatory compounds from Cryptostegia 
grandiflora and get new insights into the related molecular mechanisms.

\section{Methods \\ Reagents}

12-O-tetradecanoyl-phorbol-13-acetate (TPA), indomethacin, 2,2-diphenyl-1-picrylhydrazyl (DPPH), ascorbic acid, 2,2'-azinobis-(3-ethylbenzothiazoline-6-sulfonic acid) (ABTS), potassium persulfate $\left(\mathrm{K}_{2} \mathrm{~S}_{2} \mathrm{O}_{8}\right)$, Dulbecco's Modified Eagle Medium (DMEM), L-glutamine, antibiotics (Penicillin-Streptomycin), dimethyl sulfoxide (DMSO), trypan blue, lipopolysaccharides from Escherichia coli serotype 0127:B8 (LPS), (N-[[3-(aminomethyl)phenyl] methyl]-ethanimidamide dihydrochloride $(1400 \mathrm{~W})$, rofecoxib, sodium nitrite $\left(\mathrm{NaNO}_{2}\right)$, sodium nitroprusside (SNP), N-(1,1-naphthyl)ethylenediamine dihydrochloride, sulfanilamide, Phosphate Buffer Saline (PBS) tablets, $O$-Dianisidine, ethylenediaminetetraacetic acid (EDTA), hematoxylin and eosin were purchased from SigmaAldrich (St. Louis, MO, USA). fetal bovine serum (FBS) was obtained from GIBCO (Gaithersburg, MD, USA). Hydrogen peroxide $\left(\mathrm{H}_{2} \mathrm{O}_{2}\right)$, hexadecyl-trimethylammonium bromide (HETAB), and 3-(4,5-dimethyl-thiazol-2-yl)-2,5diphenyl-tertazolium bromide (MTT) from Calbiochem ${ }^{\circ}$ (San Diego, CA, USA). Organic solvents were analytical grade and obtained from Mallinckrodt Baker (San Diego, CA, USA).

\section{Plant material}

Leaves of Cryptostegia grandiflora (Apocynaceae) were collected at Pueblo Nuevo, Bolivar, Colombia ( $4^{\circ} 10^{\circ} 44^{\prime}$ 33" N; 75 15' 28" W; elevation 3 m.a.s.l.), in March 2011. The plant material was identified by Felipe A. Cardona N., and the voucher specimen has been deposited with the identification number HUA-175330 at the Herbarium University of Antioquia, Medellin, Colombia.

\section{Preparation of ethanol extract and primary fractions}

Dried and powdered leaves (689.9 g) were exhaustively extracted with ethanol by maceration at room temperature $\left(25 \pm 3^{\circ} \mathrm{C}\right)$. The extract was then filtered and concentrated in a rotary evaporator under controlled temperature (35$45^{\circ} \mathrm{C}$ ) and reduced pressure. A portion of the concentrated total extract $(10 \mathrm{~g})$ was fractioned using liquid/liquid partition procedures with ether $(1.4 \mathrm{~g})$, dichloromethane (1.5 g), and methanol $(3.8 \mathrm{~g})$.

\section{Experimental animals}

Female ICR mice weighing $20-25$ g were provided by Instituto Nacional de Salud, Colombia. Animals were allowed to acclimatize for 10 days before use and fed with standard rodent food and water ad libitum. They were housed in filtered-capped polycarbonate cages and kept in a controlled environment with temperature at $22 \pm 3^{\circ} \mathrm{C}$ and relative humidity between 65 to $75 \%$, under a cycle of $12 \mathrm{~h} \mathrm{light/darkness.} \mathrm{All} \mathrm{the} \mathrm{procedures} \mathrm{were} \mathrm{per-}$ formed in accordance with ethical guidelines on the care and use of animals in laboratory research, which were approved by the Ethics Committee of the University of Cartagena.

\section{TPA-induced acute ear edema}

The edema was induced by topical application of TPA $(2.5 \mu \mathrm{g} /$ ear $)$ in acetone, according to the method described by De Young et al. [30]. Mice in groups $(n=6)$ were treated on the inner and outer surfaces of the right ear with an acetone solution containing test extracts/ fractions from Cryptostegia grandiflora leaves $(1 \mathrm{mg} / \mathrm{ear}$ in $20 \mu \mathrm{L}$ of vehicle) or Indomethacin $(0.5 \mathrm{mg} / \mathrm{ear}$ in $20 \mu \mathrm{L}$ of vehicle), as reference drug. At the same time, the TPA solution was applied to both faces of the right ear. The left ear received only acetone, as a control. Four hours after the inflammation induction, animals were sacrificed by cervical dislocation and a disk (6 $\mathrm{mm}$ diameter) was removed from both ears (treated and untreated) and individually weighed on an Ohaus Pioneer ${ }^{\mathrm{Tm}}$ (PA214) analytical balance. The degree of edema was indicated by the increase in the weight of the right ear disk over the left. The antiinflammatory activity was expressed as percentage of the inhibition of edema in treated groups in comparison to control group (vehicle) [10].

Histopathologic analysis was performed according to standard protocols [31]. Ear samples were preserved in buffered formalin, embedded in paraffin, cut into $5 \mu \mathrm{m}$ sections, and stained with hematoxylin eosin. Subsequently, ear tissue was analyzed by a blinded pathologist using light microscopy, which assessed the presence of edema, epidermal hyperplasia/hypertrophy, hyperkeratosis, infiltration of mononuclear and polymorphonuclear cells, connective tissue disruption, and dermal fibrosis, using a scale of 0 to 4 ( 0 , none; 1 , mild; 2 , mild; 3 ; moderate; 4 , severe).

\section{Myeloperoxidase (MPO) assay}

MPO activity was measured according to the method by [32]. Ear tissue was weighed and homogenized in $10 \mathrm{vol}$ of $50 \mathrm{mM}$ PBS, $\mathrm{pH}$ 7.4. The homogenate was centrifuged at $4000 \mathrm{rpm}$ for $30 \mathrm{~min}$ at $4^{\circ} \mathrm{C}$. The pellet was again homogenized in $10 \mathrm{vol}$ of $50 \mathrm{mM}$ PBS, pH 6.0, containing $0.5 \%$ HETAB. The homogenate was subjected to cycles of freezing/thawing and brief periods of sonication (15 s) and centrifugation at $4000 \mathrm{rpm}$ for $10 \mathrm{~min}$ at $4^{\circ} \mathrm{C}$. Supernatants $(20 \mu \mathrm{L})$ were mixed with $50 \mu \mathrm{L}$ of $o$-dianisidine dihydrochloride $(0.067 \%)$ and $50 \mu \mathrm{L}$ of hydrogen peroxide $(0.003 \%)$ in each well of a 96-well microplate, and incubated for $5 \mathrm{~min}$. Enzyme activity was determined by measuring changes in the Optical Density at $450 \mathrm{~nm}\left(\mathrm{OD}_{450}\right)$, using a microplate reader (Multiscan EX Thermo ${ }^{\circ}$ ), and 
expressed as the inhibition percentage of MPO levels calculated against the absorbance presented by the control group.

\section{Cell culture}

The murine RAW 264.7 macrophage-like cell line was obtained from the American Type Culture Collection (TIB-71; Rockville, MD, USA) and routinely cultured in DMEM supplemented with $2 \mathrm{mM} \mathrm{L-glutamine,} \mathrm{antibi-}$ otics $(100 \mathrm{IU} / \mathrm{mL}$ of penicillin $-100 \mu \mathrm{g} / \mathrm{mL}$ streptomycin) and heat-inactivated $\mathrm{FBS}$ at $37^{\circ} \mathrm{C}$ in a humidified atmosphere containing $5 \% \mathrm{CO}_{2}$.

\section{MTT assay}

The mitochondrial-dependent reduction of MTT to formazan was used to assess the possible cytotoxic effects of Cryptostegia grandiflora leaves on RAW 264.7 cells $[33,34]$. Macrophages $\left(2 \times 10^{5}\right.$ cells $\left./ \mathrm{mL}\right)$ were cultured at $37^{\circ} \mathrm{C}$ and allowed to grow to confluence. Subsequently, the culture medium was replaced with various concentrations of test extracts/fractions or $1400 \mathrm{~W}$ for $30 \mathrm{~min}$, followed by stimulation with of E. coli LPS $(1 \mu \mathrm{g} / \mathrm{mL})$. Control group was incubated with the same amount of DMSO. Triton X-100 (2\%) was used as positive control. After $24 \mathrm{~h}$, the medium was removed and cells incubated with MTT solution ( $3 \mathrm{mg} / \mathrm{mL}$ ). Four hours later medium was carefully aspirated, formazan crystals were dissolved in $\mathrm{DMSO}$, and $\mathrm{OD}_{550}$ was measured using a microplate reader (Multiscan EX Thermo ${ }^{\circ}$ ).

\section{NO. and PGE2 production}

The evaluation of the anti-inflammatory activity was performed in a manner similar to that described for cell viability. In brief, RAW 264.7 cells $\left(2 \times 10^{5}\right.$ cells $\left./ \mathrm{mL}\right)$ were allowed to grow to confluence at $37^{\circ} \mathrm{C}$. The adherent cells were treated for $30 \mathrm{~min}$ with various concentrations of fractions from Cryptostegia grandiflora leaves, 1400 $\mathrm{W}$ or Rofecoxib, and stimulated with LPS $(1 \mu \mathrm{g} / \mathrm{mL})$. Control cells were cultured under the same conditions but were not exposed to the effect of LPS. Twenty four hours later, culture supernatants were collected and stored at $-20^{\circ} \mathrm{C}$ until use.

$\mathrm{NO} \cdot$ release was determined spectrophotometrically by the accumulation of nitrite $\left(\mathrm{NO}_{2}^{-}\right)$, using the Griess reaction [35]. Briefly, $100 \mu \mathrm{L}$ of cell culture medium was mixed with $100 \mu \mathrm{L}$ of Griess reagent (1:1 mixture of $0.1 \% \mathrm{~N}$-(1-naphthyl) ethylenediamine dihydrochloride and $1 \%$ sulfanilamide in $\left.5 \% \mathrm{H}_{3} \mathrm{PO}_{4}\right)$, and incubated at room temperature for $5 \mathrm{~min}$. The $\mathrm{OD}_{550}$ of the samples was measured using a microplate reader (Multiscan EX Thermo $\circ^{\circ}$ ) and compared with a standard curve prepared with $\mathrm{NaNO}_{2}(1-200 \mu \mathrm{M})$. Levels of PGE2 were determined using commercially available competitive ELISA kits (R\&D Systems, Minneapolis, MN) according to the manufacturer's instructions. Final results were expressed as $\mathrm{pg} / \mathrm{mL}$ of supernatant.

\section{NO radical scavenging effect}

NO-scavenging effect of fractions of Cryptostegia grandiflora leaves was determined by the method of [36] with some modfications. Sodium nitroprusside (SNP) in aqueous solution spontaneously generates $\mathrm{NO}$ - which interacts with oxygen to produce $\mathrm{NO}_{2}^{-}$ions that can be estimated using Griess reagent. Scavengers of $\mathrm{NO}$ - compete with oxygen, leading to reduced production of $\mathrm{NO}_{2}^{-}$[37]. Briefly, SNP (5 mM) in PBS, pH 7.4, was mixed with test compounds and incubated at $25^{\circ} \mathrm{C}$ for $120 \mathrm{~min}$. After this period, samples were incubated with an equal volume of Griess reagent for $5 \mathrm{~min}$. The $\mathrm{OD}_{550}$ was measured using a microplate reader (Multiscan EX Thermo ${ }^{\circ}$ ) and compared with standard solutions of $\mathrm{NaNO}_{2}(1-200 \mu \mathrm{M})$.

\section{DPPH radical scavenging activity}

DPPH-scavenging effect was determined using the method described by [38], with some modifications. In brief, $75 \mu \mathrm{L}$ of fractions from Cryptostegia grandiflora and ascorbic acid, at various concentrations, were plated into 96-well plates, mixed with $150 \mu \mathrm{L}$ of DPPH $(100 \mu \mathrm{g} / \mathrm{mL}$; in methanol), and incubated at room temperature $\left(25 \pm 3^{\circ} \mathrm{C}\right)$. Vehicles were used as negative controls. After $30 \mathrm{~min}$, the disappearance of DPPH radical absorption was determined at $\mathrm{OD}_{550}$ using a microplate reader (Multiscan EX Thermo ${ }^{\circ}$ ).

\section{ABTS radical scavenging activity}

ABTS-scavenging effect was determined using the method described by [39], whit modifications. Briefly, $10 \mu \mathrm{L}$ of various concentrations of fractions from Cryptostegia grandiflora or ascorbic acid, used as positive controls, were mixed with $190 \mu \mathrm{L}$ of ABTS (3.5 mM; in ethanol) and $\mathrm{K}_{2} \mathrm{~S}_{2} \mathrm{O}_{8}(1.25 \mathrm{mM})$. The mixture was incubated at room temperature for $5 \mathrm{~min}$. After this time, the disappearance of ABTS radical absorption was determined at $\mathrm{OD}_{405}$ using a microplate reader (Multiscan EX Thermo ${ }^{\circ}$ ).

\section{Statistical analysis}

Results from three independent assays were expressed as mean \pm standard error of the mean (S.E.M) and analyzed using one-way analysis of variance (ANOVA), followed by Dunnett's or Tukey's post hoc test, to determine the differences between groups. Values of $\mathrm{p}<0.05$ were considered significant. $\mathrm{LC}_{50}$ and $\mathrm{IC}_{50}$ values were calculated using non-linear regression analysis and expressed as the mean and its $95 \%$ confidence interval.

\section{Competing interest}

The authors declare that they have no competing interests. 


\section{Authors' contributions}

JC: Magister Student of Pharmacology - Carried out the in vivo anti-inflammatory assays as well as the evaluation of free radical scavenging activity. YO: Ph.D. Student - Carried out the in vitro anti-inflammatory assays using macrophages cell culture and helped to draft the manuscript. LF: Principal Investigator - Conceived and designed the study, collaborated conducting the in vivo tests, and writing and reviewing the manuscript. All authors read and approved the final manuscript.

\section{Acknowledgments}

This work was supported by the University of Cartagena, Colombia [grant number 03-2011 and 054-2013]. Authors are grateful to Lilia Anillo Santis, who kindly contributed with her skills in cell culture. We also wish to thank the Young Investigators and Innovators Program "Virginia Gutiérrez de Pineda", from Colciencias, Colombia that sponsors JC and YO.

Received: 24 June 2014 Accepted: 4 July 2014

Published: 10 July 2014

\section{References}

1. Conroy H, Mawhinney L, Donnelly S: Inflammation and cancer: macrophage migration inhibitory factor (MIF) - the potential missing link. QJM 2010, 103:831-836.

2. Hutchinson JL, Rajagopal SP, Sales KJ, Jabbour HN: Molecular regulators of resolution of inflammation: potential therapeutic targets in the reproductive system. Reproduction 2011, 142:15-28.

3. Shelton RC, Miller AH: Eating ourselves to death (and despair): the contribution of adiposity and inflammation to depression. Prog Neurobiol 2010, 91:275-299.

4. Bayarsaihan D: Epigenetic mechanisms in inflammation. J Dent Res 2011, 90:9-17.

5. Kowal K, Silver R, Sławińska E, Bielecki M, Chyczewski L, Kowal-Bielecka O: CD163 and its role in inflammation. Folia Histochem Cytobiol 2011, 49:365-364.

6. Mustafa A, El-Medany A, Hagar HH, El-Medany G: Ginkgo biloba attenuates mucosal damage in a rat model of ulcerative colitis. Pharmacol Res 2006, 53:324-330

7. Amirghofran Z: Herbal Medicines for Immunosuppression. Iran J Allergy Asthma Immunol 2012, 11:111-119.

8. Choi EM, Hwang JK: Investigations of anti-inflammatory and antinociceptive activities of Piper cubeba, Physalis angulata and Rosa hybrida. J Ethnopharmacol 2003, 89:171-175.

9. Khan AQ, Khan R, Qamar W, Lateef A, Ali F, Tahir M, Muneeb UR, Sultana S: Caffeic acid attenuates 12-O-tetradecanoyl-phorbol-13-acetate (TPA)-induced NF-KB and COX-2 expression in mouse skin: abrogation of oxidative stress, inflammatory responses and proinflammatory cytokine production. Food Chem Toxicol 2012, 50:175-183.

10. Franco LA, Matiz GE, Calle J, Pinzón R, Ospina LF: Antiinflammatory activity of extracts and fractions obtained from Physalis peruviana L. calyces. Biomedica 2007, 27:110-115.

11. Augustus G, Jayabalan M, Seiler G: Cryptostegia grandiflora-a potential multi-use crop. Ind Crop Prod 2000, 11:59-62.

12. Albuquerque TM, Alencar N, Figueiredo JG, Figueiredo IS, Teixeira CM, Bitencourt FS, Secco DD, Araújo ES, Ana Maria Leão C, Ramos MV: Vascular permeability, neutrophil migration and edematogenic effects induced by the latex of Cryptostegia grandiflora. Toxicon 2009, 53:15-23.

13. Singh B, Sharma RA, Vyas GK, Sharma P: Estimation of phytoconstituents from Cryptostegia grandiflora (Roxb.) R. Br. in vivo and in vitro. II. Antimicrobial screening. 2011.

14. Mukherjee PK, Gunasekhran R, Subburaju T, Dhanbal SP, Duraiswamy B, Vijayan P, Suresh B: Studies on the antibacterial potential of Cryptostegia grandiflora R. Br. (Asclepiadaceae) extract. Phytother Res 1999, 13:70-72.

15. Nagaraju N, Rao KN: A survey of plant crude drugs of rayalaseema, Andhra Pradesh, India. J Ethnopharmacol 1990, 29:137-158.

16. Ray S, Sheikh M, Mishra S: Ethnomedicnal plants used by tribals of east Nimar region, Madhya Pradesh. Ind J Tradnl Knowledge 2011, 10:367-371.

17. Vijayan P, Raghu C, Ashok G, Dhanaraj S, Suresh B: Antiviral activity of medicinal plants of Nilgiris. Indian J Med Res 2004, 120:24.

18. Pinto N, Morais T, Carvalho K, Silva C, Andrade G, Brito G, Veras M, Pessoa O, Rao V, Santos F: Topical anti-inflammatory potential of Physalin E from
Physalis angulata on experimental dermatitis in mice. Phytomedicine 2010, 17:740-743.

19. Murakawa M, Yamaoka $K$, Tanaka Y, Fukuda Y: Involvement of tumor necrosis factor (TNF)-a in phorbol ester 12-O-tetradecanoylphorbol-13-acetate (TPA)-induced skin edema in mice. Biochem Pharmacol 2006, 71:1331-1336.

20. Lau D, Baldus S: Myeloperoxidase and its contributory role in inflammatory vascular disease. Pharmacol Ther 2006, 111:16-26.

21. Silva FV, Guimaraes AG, Silva ER, Sousa-Neto BP, Machado FD, Quintans-Junior $\sqcup$, Arcanjo DD, Oliveira FA, Oliveira RC: Anti-inflammatory and anti-ulcer activities of carvacrol, a monoterpene present in the essential oil of oregano. J Med Food 2012, 15:984-991.

22. Uzkeser H, Cadirci E, Halici Z, Odabasoglu F, Polat B, Yuksel TN, Ozaltin S, Atalay F: Anti-Inflammatory and Antinociceptive Effects of Salbutamol on Acute and Chronic Models of Inflammation in Rats: Involvement of an Antioxidant Mechanism. Mediat Inflamm 2012, 2012:1-10.

23. Lantz R, Chen G, Solyom A, Jolad S, Timmermann B: The effect of turmeric extracts on inflammatory mediator production. Phytomedicine 2005, 12:445-452.

24. Schairer DO, Chouake JS, Nosanchuk JD, Friedman AJ: The potential of nitric oxide releasing therapies as antimicrobial agents. Virulence 2012, 3:1.

25. Dannhardt G, Kiefer W: Cyclooxygenase inhibitors-current status and future prospects. Eur J Med Chem 2001, 36:109-126.

26. Han J, Shuvaev W, Muzykantov VR: Targeted interception of signaling reactive oxygen species in the vascular endothelium. Ther Deliv 2012, 3:263-276.

27. Hanumanthappa SK, Hanumanthappa M, Venkatarangaiah K, Krishnappa P, Gupta RKP: Analgesic activity of Cryptostegia grandiflora (Roxb.) R.br. leaves methanol extract using mice. Asian Pacific J Tropical Dis 2Supplement 2012, 1:S494-S498.

28. García-Lafuente A, Guillamón E, Villares A, Rostagno M, Martínez J: Flavonoids as anti-inflammatory agents: implications in cancer and cardiovascular disease. Inflamm Res 2009, 58:537-552.

29. Kumar VL, Chaudhary P, Ramos MV, Mohan M, Matos MP: Protective Effect of Proteins Derived from the Latex of Calotropis procera against Inflammatory Hyperalgesia in Monoarthritic Rats. Phytother Res 2011, 25:1336-1341.

30. De Young LM, Kheifets JB, Ballaron SJ, Young JM: Edema and cell infiltration in the phorbol ester-treated mouse ear are temporally separate and can be differentially modulated by pharmacologic agents. Inflamm Res 1989, 26:335-341

31. Langer Lilleholt L, Johansen C, Arthur JSC, Funding A, Bibby BM, Kragballe K, Iversen $\mathrm{L}$ : Role of $\mathrm{p} 38$ mitogen-activated protein kinase isoforms in murine skin inflammation induced by 12-0-tetradecanoylphorbol 13-acetate. Acta Derm Venereol 2011, 91:271-278.

32. Bradley PP, Priebat DA, Christensen RD, Rothstein G: Measurement of cutaneous inflammation: estimation of neutrophil content with an enzyme marker. J Investig Dermatol 1982, 78:206-209.

33. Mosmann T: Rapid colorimetric assay for cellular growth and survival: Application to proliferation and cytotoxicity assays. J Immunol Methods 1983, 65:55-63.

34. Ferrari M, Fornasiero MC, Isetta AM: MTT colorimetric assay for testing macrophage cytotoxic activity in vitro. J Immunol Methods 1990, 131:165-172.

35. Green LC, Wagner DA, Glogowski J, Skipper PL, Wishnok JS, Tannenbaum SR: Analysis of nitrate, nitrite, and nitrate in biological fluids. Anal Biochem 1982, 126:131-138.

36. Sreejayan RMNA: Nitric Oxide Scavenging by Curcuminoids. J Pharm Pharmacol 1997, 49:105-107.

37. Kumaran A, Joel KR: Antioxidant and free radical scavenging activity of an aqueous extract of Coleus aromaticus. Food Chem 2006, 97:109-114.

38. Silva BM, Andrade PB, Valentão P, Ferreres F, Seabra RM, Ferreira MA: Quince (Cydonia oblonga Miller) fruit (pulp, peel, and seed) and jam: antioxidant activity. J Agric Food Chem 2004, 52:4705-4712.

39. Re R, Pellegrini N, Proteggente A, Pannala A, Yang M, Rice-Evans C: Antioxidant activity applying an improved ABTS radical cation decolorization assay. Free Radic Biol Med 1999, 26:1231-1237.

\section{doi:10.1186/0717-6287-47-32}

Cite this article as: Castro et al:: In vivo and in vitro anti-inflammatory activity of Cryptostegia grandiflora Roxb. ex R. Br. leaves. Biological Research 2014 47:32. 